Mauro

Mantovani

\section{Università}

Pontificia

Salesiana, Italia

mantovani@unisal.it

Recibido: 20.11.17

Aceptado: 2.04.18

\title{
"Metafísica jurídica" y "metafísica teológica": su intrínseca conexión en Suárez
}

\section{"Legal Metaphysics" and "Theological Metaphysics": their intrinsic connection in Suárez}

Resumen: Este trabajo pretende mostrar cómo se puede encontrar una conexión intrínseca entre la teoría del derecho y de la ley suareciana y las posturas metafísicas relativas a la existencia y subsistencia divinas, así comoalacuestión de la demostrabilidad de la existencia de Dios. En primer lugar, se exponen los principales elementos de la lectura que el teólogo jesuita hace en el De legibus acerca del concepto de ley, en una especie de "metafísica jurídica". En segundo lugar, se muestra cómo las temáticas antes indicadas remiten y están vinculadas a las cuestiones metafísicas fundamentales sobre la subsistencia y existencia divinas, y, en general, a toda la teología filosófica. En efecto, no se trata sólo de anclar en Dios el concepto de ley o el fundamento de la moral, sino de demostrar la conexión entre ratio juridica y ratio teologica en relación a una misma mirada de la realidad.

Palabras clave: Francisco Suárez; ley; teología; Dios.

\begin{abstract}
This work aims to demonstrate the intrinsic connection established between the law theory and the Suarecian law. It also tries to show metaphysical positions about the divine existence and subsistence, as well as the capacity of demonstrating the existence of God. In the first place, it exposes the main elements of the Jesuit theologist's interpretations regarding the concept of law in De Legibus, which corresponds to a type of "legal metaphysics". Additionally, this paper shows how the aforementioned topics connect to fundamental metaphysical questions about the divine subsistence and existence and, in general, to philosophical theology as a whole. In fact, it is not only about linking the concepts of law or of fundamental moral to God, but about demonstrating the connection between legal ratio and theological ratio regarding the same reality perspective.
\end{abstract}

Keywords: Francisco Suárez; law; theology; God. 
El cuarto centenario de la muerte de Francisco Suárez está inspirando varias iniciativas para estudiar su obra y sacar a la luz su actualidad y significatividad ${ }^{1}$. Participando en este número especial de la Revista Jurídica Digital UANDES dedicado al teólogo jesuita español sobre temas principalmente de filosofía jurídica, deseo contribuir con un trabajo que pretende mostrar cómo se puede encontrar una conexión intrínseca entre la teoría del derecho y de la ley suareciana y las posturas metafísicas relativas a la existencia y subsistencia divinas, y a la demostrabilidad de la existencia de Dios.

Aun no teniendo un conocimiento particularmente profundo de la doctrina del derecho del teólogo jesuita español, la referencia a algunos estudios correspondientes - a partir del interesante ensayo publicado en 1990 por M. Bastit, que documenta las variaciones de la noción de ley de Santo Tomás a Francisco Suárez, pasando por autores como Juan Duns Escoto y Guillermo de Occam(Bastit, 1990), nos permitirá proponer esta relación.

La primera parte de estas páginas estará dedicada por tanto a algunos elementos de la lectura que el teólogo jesuita, en el De legibus ${ }^{2}$, propone del concepto de ley, con una especie, casi, de "metafísica jurídica"; en la segunda parte, en cambio, veremos cómo las temáticas antes indicadas remiten y están profundamente vinculadas a las cuestiones metafísicas fundamentales relativas a la subsistencia y existencia divinas, y a la teología filosófica. No se trata sólo de anclar en Dios los conceptos de ley o el fundamento de la moral ${ }^{3}$, sino de demostrar la conexión entre ratio juridica y ratio teologica en relación a una misma óptica de lo real.

¿Cómo ver, en fin, el derecho y la ley: como elementos que existen dentro o fuera de una referencia a un orden intrínseco del mundo, de la misma realidad creada y, además, a la misma realidad divina? La pregunta, que obviamente remite a un interrogante fundamental de carácter metafísico, porque, en definitiva, atiende a la cuestión de si la realidad misma tiene un orden y de este derive la "capacidad" de suministrar indicaciones sobre la propia ley, toca un punto historiográfico crucial en la relación entre pensamiento clásico y medieval y pensamiento moderno, y, aún antes, entre nominalismo, realismo y pensamiento de la modernidad.

\footnotetext{
1 Véanse, solo a título de ejemplo, los Convenios previstos en Salamanca (Entre el Renacimiento y la Modernidad: Francisco Suárez [1548-1617], el 30-31 de marzo 2017), Pamplona (Francisco Suárez: Escolástica y Mundo Moderno, el 26-28 de abril 2017), Porto (Pensar o Barroco em Portugal, 26-28 de julio 2017), São Leopoldo (RS) en Brasil (Metaphysics and Practical Philosophy: the Actuality of Francisco Suárez's Thought 400 Years Later, el 25-28 de septiembre 2017) y Roma (en la Pontificia Universidad Gregoriana, el 2324 de octubre 2017). A propósito del autor, señalamos aquí algunos estudios útiles de manera ejemplicativa, remitiendo también a las abundantes bibliografías online ofrecidas en Scholasticon y por Sidney Penner (http://www.sydneypenner.ca/bib.shtml). Mahieu, L. (1921). François Suarez: Sa philosophie et les rapports qu'elle a avec sa théologie. Paris: Desclée-Picard; Grabmann, M. (1926). Die Disputationes Metaphysicae des Franz Suarez in ihrer methodischen Eigenart und Fortentwicklung. En M. Grabmann (Ed.). Mittelalterliches Geistesleben. Abhandlungen zur Geschichte der Scholastik und Mystik. (pp. 525-560). München: Max Hueber; Giacon, C. (1946). La Seconda scolastica, Milano: Fratelli Bocca; Larrainzar, C. (1976). Una introducción a Francisco Suárez. Pamplona: Eunsa; Castellote, S. (1980). Der Stand der heutigen Suárez-Forschung auf Grund der neu gefundenen Handschriften. Philosophisches Jahrbuch, 87, 134142; Cardoso, A., Martins, A. M. y Ribeiro dos Santos, L. (Eds.). (1999). Francisco Suárez (1548-1617): Tradição e Modernidade, Lisboa: Ediçoes Colibri; Pereira, J. (2007). Suárez: Between Scholasticism and Modernity. Milwaukee: Marquette University; Coujou, J.-P. (2010). Bibliografía suareciana, Pamplona: Universidad de Navarra; Sgarbi M., M. (Ed.). (2010). Francisco Suárez and His Legacy. Milano: Vita e Pensiero; Hill, B. y Lagerlund, H. (Eds.). (2012). The Philosophy of Francisco Suárez. Oxford: Oxford University Press; Poncela, G.Á. (2012). Una aproximación bibliográfica a Francisco Suárez como comentador de la Suma Teológica. Cauriensia, 7, 165-173; Schwartz, D. (Ed.). (2012). Interpreting Suárez: Critical Essays. Cambridge: Cambridge University Press; Moita, G.P. (2014). A Modernidade Filosófica de Francisco Suárez. Lisboa: Imprensa Nacional-Casa da Moeda; Novák, L. (Ed.). (2014). Suárez’s Metaphysics in Its Historical and Systematic Context. Berlin: De Gruyter; Salas, V. y Fastiggi, R. (Eds.). (2015). A Companion to Francisco Suárez. Leiden: Brill.

${ }^{2}$ Por lo que respecta a las fuentes relativas a Suárez, hacemos referencia a los volúmenes de André, M. y Berton, C. (Ed.). (1856-1878). Opera Omnia (Editio nova). Paris: Vivès. Para los textos en lengua española de las Disputationes Metaphysicae, utilizamos Suárez, F. (1962). Disputaciones Metafísicas [DM], S. Rábade, S. Caballero Sánchez y A. Piugcerver Zanón (Eds.). Madrid: Biblioteca Hispánica de Filosofía-Gredos.

${ }^{3}$ A tal propósito véanse, por ejemplo, Desjardins, C. (1963). Dieu et l'obligation morale: L'argument déontologique dans la scolastique récente. Paris: Descleé; Owen, H.P. (1965). The moral argument for Christian Theism. London: Allen; Roth, R. (1980). Moral obligation and God. The Newscolasticism 54, 265 278; Roth, R. (1985). Moral obligation: With or without God. The Newscolasticism, 59, $471-474$.
} 


\section{1. "Metafísica jurídica" suareciana}

\section{1. ¿Qué "ratio legis"?}

Es indudable la importancia de Francisco Suárez en la historia del pensamiento jurídico ${ }^{4}$, por su presentarse casi como un "antes y después" entre la escolástica y la modernidad, y por la indudable influencia que el teólogo jesuita ejerció en muchos sucesores suyos en las principales cátedras europeas de metafísica hasta Kant, y es precisamente entre ellos donde se han dado los mayores exponentes de la escuela del derecho natural moderno ${ }^{5}$.

Suárez representa también una encrucijada respecto a las interpretaciones que se han elaborado del pensamiento de Tomás de Aquino. El Doctor Angélico había aportado en la Suma Teológica una poderosa reflexión relativa al tema de la ley y de sus tipologías"; para él "toda ley se deriva de la ley eterna en la medida en que participa de la recta razón" (Tomás de Aquino, Suma Teológica, la llae, q. 93, art. 3), porque la razón de la divina sabiduría - en cuanto todas las cosas han sido creadas por ella - tiene carácter de arte, de ejemplar, de idea, así esa misma razón de la sabiduría divina, en cuanto mueve todas las cosas hacia su debido fin, tiene carácter de ley. Y, según esto, la ley eterna no es otra cosa que la razón de la divina sabiduría en cuanto dirige todos los actos y movimientos (Tomás de Aquino, Suma Teológica, la Ilae, q. 93, art. 1).

La sabiduría de Dios para el Aquinate es providencia, amor que cuida. Y respecto a los hombres, ello sucede de manera distinta que respecto a los seres que no son personas: no desde el exterior, a través de las leyes de la naturaleza física, sino "desde dentro", mediante la razón, que conociendo con la luz natural la ley eterna de Dios, está por eso mismo en situación de indicar al hombre la justa dirección de su libre actuar (Tomás de Aquino, Suma Teológica, la llae, q. 90, art.4, ad 1m.). En este

\footnotetext{
${ }^{4}$ A título de ejemplo, Farrell, W. (1930). The natural moral law of S. Thomas and Suarez. Ditchling: St. Dominic's Press; Ambrosetti, G. (1948). La filosofia della legge di Suarez. Roma: Studium; Arntz, J. (1970). Lo sviluppo del pensiero giusnaturalistico all'interno del tomismo, en F. Boeckle (Ed.). Dibattito sul diritto naturale (pp. 115-148). Brescia: Queriniana,; Carbonnier, J. (1979). L'inflation des lois: Essais sur les lois. Paris: Presses Universitaires de France; Bastit, M. (1989). Interprétation analogique de la loi et analogie de l'être chez Suárez: de la similitude à l'identité. Les Etudes philosophiques, 44, 429-443; Bastit, M. (1990). Naissance de la loi moderne. La pensée de la loi de saint Thomas à Suárez. Paris: PUF; Andereggen, I. (2011). El bien metafísico fundamento de la ley, según Francisco Suárez. Divinitas, 54 (3), 257-274; Contreras, S. (2012). La ratio legis en la teología de Suárez y Santo Tomás. Teología y Vida, 53 (4), 503-520; Coujou, J.-P. (2012). Droit, anthropologie \& politique chez Suárez. Perpignan: Artège; Coujou, J.-P. (2015). Political Thought and Legal Theory in Suárez, en V. Salas y R. Fastiggi, (Eds.). A Companion to Francisco Suárez (pp. 29-71). Leiden: Brill; Bach, O., Brieskorn, N. y Stiening, G. (Eds.). (2013). "Auctoritas omnium legum": Francisco Suárez' De legibus zwischen Theologie, Philosophie und Jurisprudenz. Stuttgart, Bad Cannstatt: Frommann Holzboog; Faraco, C. (2013). Breve excursus sul concetto di legge in Francisco Suárez. Colonne Ofitiche.: Percorsi di ermeneutica simbolica (pp. 73-84). Napoli: Luciano; García Cuadrado, J.A. (Ed.). (2014). Los fundamentos antropológicos de la ley en Suárez. Pamplona: Eunsa; Murphy, M.C. (2014). Suárez's 'Best Argument' and the Dependence of Morality on God. Quaestiones Disputatae, 5 (1), 30-42; Velázquez, L. (2014). Presupuestos antropológicos de la concepción de la ley natural en Suárez (a propósito de Dios creador/legislador), en J.A. García Cuadrado (Ed.). Los fundamentos antropológicos de la ley en Suárez (pp. 75-88). Pamplona: Eunsa; Pace, P. (2015). Suárez and the Natural Law. En V. Salas y R. Fastiggi R. (Eds.). A Companion to Francisco Suárez (pp. 274-296). Brill, Leiden; Kirstin, B., Fuchs, M.J., Simmermacher, D. y Spindler A. A. (Eds.) (2016). The Concept of Law (lex) in the Moral and Political Thought of the 'School of Salamanca', Leiden: Brill.

${ }^{5}$ P. Mesnard, por ejemplo, ha mostrado cómo Leibniz, Grozio y Hobbes presentan en muchas de sus obras continuas referencias que provienen directamente o, al menos indirectamente, del pensamiento de Suárez. Cf. Mesnard, P. (1949). Comment Leibniz se trouve placé dans le sillage de Suárez. Archives de Philosophie, 18, 7-32.

${ }^{6}$ Ver, por ejemplo, Cotta, S. (1955). Il concetto di legge nella Summa Theologiae di San Tommaso d'Aquino, Torino: Giappichelli; Abbà, G. (1983). Lex et virtus. Studi sull'evoluzione della dottrina morale di San Tommaso d'Aquino, Roma: Las; Osuna Fernández-Largo, A. (1989). Tratado de la ley en general, en Tomás de Aquino (1989), Suma Teológica Il (pp. 693-702), Madrid: BAC; Blázquez Fernández, N. (1989). Tratado de la ley antigua y nueva, en Tomás de Aquino, Suma Teológica II (pp. 761-776). Madrid: BAC.
} 
contexto, como expresión humana de la ley eterna de Dios, se sitúa la ley natural:

La criatura racional, entre todas las demás, está sometida a la divina Providencia de una manera especial, ya que se hace partícipe de esa providencia, siendo providente sobre sí y para los demás. Participa, pues, de la razón eterna; esta le inclina naturalmente a la acción debida y al fin. Y semejante participación en la criatura racional se llama ley natural (Tomás de Aquino, Suma Teológica, la llae, q. 91, art. 2).

Esta visión se confrontó muy pronto con las perspectivas nominalistas, que antes de alcanzar el pensamiento de los juristas ya se habían planteado desde hacía tiempo en oposición al pensamiento del Aquinate. En clave nominalista, el discurso ético fue entendido ante todo como búsqueda de la ley moral que se debe observar, y en este sentido fueron Juan Duns Escoto y Guillermo de Occam quienes la dotaron de sus acentos más característicos ${ }^{7}$.

A inicios del siglo $\mathrm{XVI}$, se podría afirmar que tres corrientes principales dominaban la teología moral: el occamismo, enseñado en las facultades de Tubinga y de París, el humanismo de Erasmo de Rotterdam, y el tomismo, que registraba un creciente aumento de consenso en Alemania, Francia e Italia. Si el punto de encuentro de estas tres corrientes es reconocido en el ingenio y en la obra del dominicano español Francisco de Vitoria, que supuso el punto de partida de la segunda escolástica, fue con Gabriel Vázquez (1600) y en concreto con Suárez, que el tomismo se dirigió hacia una "moral natural", racional, aunque últimamente fundada siempre en la acción creadora de Dios. Será la obra de Suárez la que tendrá una enorme influencia histórica: a partir de Grocio (1751), la ética teológica de la ley sufrió una progresiva secularización que tuvo sucesivamente como resultado, tanto nuevas figuras de ética, típicamente modernas, como una ética secularizada de la ley moral, que va del iusnaturalismo a Kant. A partir del iusnaturalismo se desarrolló así, por obra de Hobbes, una ética pensada como búsqueda de reglas para la colaboración social, y esta se encuentra hoy ampliamente difundida en muchas versiones, desde las contractualistas, a las convencionalistas, a la ética del discurso (Abbà, 1995).

Los puntos principales de la doctrina nominalista de la ley se transmitieron entonces y se desarrollaron a través de la constitución de una verdadera escuela nominalista casi a las puertas de la edad moderna, y la obra magistral de Francisco Suárez apareció, a este respecto, como la síntesis más amplia que se esforzó por conciliar un cierto número de elementos de la tradición realista tomista y aristotélica con el aporte del pensamiento nominalista $\mathrm{y}$, en particular, transmitiendo al pensamiento jurídico moderno los principios voluntaristas extraídos de Escoto y Occam (Mesnard, 1949; Courtine, 1979).

El tratado De legibus del teólogo jesuita está, en efecto, fundado en un excelente conocimiento de la tradición, no solo la jurídica sino también la general del conjunto de la literatura teológica medieval y del renacimiento, a la cual, Suárez a menudo se refiere. En este sentido, en su caso se puede hablar de "modernidad tradicional"8. Los Commentaria ac disputationes in primam secundae D. Thomae De legibus, seu Legislatore Deo: Tractatus de legibus, utriusque fori hominibus utilis, in decem libros dividitu' $^{19}$ constituyen el comentario a las qq. 90-108 de la I-llae de la Summa. Introduzcámonos ahora en algunos elementos sobresalientes.

\footnotetext{
${ }^{7}$ Por ejemplo, Owens, J. (1957). Common nature: a point of comparison between thomistic and scotist metaphysics. Medieval Studies, 19, 1-14.

${ }^{8}$ Así se lee en la Editorial (1949). Suárez, modernité traditionelle de sa philosophie. Archives de Philosophie, 18, 4-6.

${ }^{9}$ Suãrez, F. (1856). Tractatus de legibus, en Opera Omnia (Editio nova), C. Breton (Ed.). Paris: Vivès, vol. 5-6. El tratamiento, en diez libros, está así subdividido: I: De natura legis in communi, de ejusque causis, et effectibus (vol. V, pp. 1-84); II. De lege aeterna, naturali et jure gentium (vol. V, pp. 85-172); III. De lege positiva humana secundum se, et prout in pura hominis natura spectari potest, quae lex etiam civilis dicitur (vol. V, pp. 175-324); IV. De lege positiva canonica (vol. V, pp. 326-410); V. De varietate legum humanarum, et praesertim de poenalibus et odiosis (vol. V, pp. 412-562); VI. De interpretatione, mutatione et cessatione legum humanarum (vol. VI, pp. 1-133); VII. De lege non scripta quae consuetudo appellatur (vol. VI, pp. 134-223); VIII. De lege humana favorabili seu de privilegio (vol. VI, pp. 225-417); IX. De lege divina positiva veteri (vol. VI, pp. 419-548); X. De lege nova divina (vol. VI, pp. 550-597).
} 
1.2. El De legibus suareciano: aspectos ético-jurídicos y antropológico-metafísicos

El Aquinate había subdividido el tratamiento de la ley en dos partes. En la primera, se define la ley, se expresa una ratio legis, mientras que en la segunda, se muestran las diversas realizaciones de la noción de ley, en la ley eterna, la ley natural, etc. Esta segunda parte está organizada por Tomás según dos órdenes, de los cuales el primero y más visible para el lector parte de la ley eterna y desciende hasta la ley humana. Dentro del texto del Doctor Angélico está, no obstante, presente un segundo orden, según el cual las leyes están organizadas a través de una jerarquía de fines cada vez más elevados, hacia una ley que realiza la unidad de estos. Si el primero de estos órdenes es incontestablemente el más evidente, la razón puede ser sin duda hallada en la característica misma de la Summa, obra teológica en la que el autor se esfuerza por explicar cada cosa a la luz del ser primero que él ya posee, según un orden de participación a partir del primero, que es el más evidente. No menos importante, sin embargo, es para Tomás el orden que organiza las diversas leyes de fin en fin hacia una ley, la ley última: este es el orden que descubre la filosofía, remontando desde la ley humana a la ley eterna, en la búsqueda de un principio último.

En su aproximación a la perspectiva tomista, el teólogo Suárez trabaja exclusivamente en su Comentario en una óptica de deducción del orden de las leyes, fundada en una reducción del orden de los seres. Para efectuar su exposición de la participación de las leyes, el teólogo jesuita debe partir también de un análisis de la ratio legis. Esto le permite introducir sin dificultad su Comentario en el plano organizativo de Tomás, eliminando no obstante los conceptos que se oponen a su proyecto.

La primera cuestión, típicamente metafísica, que ante todo debe plantearse, es la de saber si las trasformaciones que se imponen al orden de las leyes, para la eliminación de la relación de proporcionalidad, repercuten o no en la ratio legis: ¿es posible conservar la ratio legis de Tomás y al mismo tiempo aplicarla solo en el orden participativo? La analogía de atribución, así como la expone Suárez, implica que sea abandonada la relación del ser a su acto: en consecuencia, el concepto de ser se ve privado de su relación real con el esse. Se puede, entonces, imaginar ya que la mutilación sufrida por el concepto de ser tendrá su corolario, en el orden de la ley, y que la ratio legis se verá de este modo privada de su fin propio para ser confinada a un orden estático, que quedará reducido a su aspecto de determinación, como el ser es reducido a su sustancia sin que pueda expresar su ejercicio. Y es esta la operación conceptual que efectivamente resulta de ello.

Esta modificación evidencia cómo con estas argumentaciones de Suárez la ley no puede ya desplegarse dentro de un campo en el que el ser no está encerrado dentro de su sustancia, sino que está en ejercicio para alcanzar su fin. La supresión de este campo no puede más que conducir a una restricción de la ley al campo sustancial, para después -en el fondo- confundirla con él. En efecto, Suárez, en el cap. XII (Quae definitio legis ex dictis conditionibus ejus colligatur) del libro I del De legibus, termina su análisis de la ley con una definición muy personal, en la cual se subrayan claramente las modificaciones sufridas por este concepto tras el alejamiento de la perspectiva de Tomás: "lex est commune praeceptum, justum ac stabile, sufficienter promulgatum" (la ley es un precepto común, justo y estable, suficientemente promulgado) ${ }^{10}$.

Su concepción limitada de la analogía, típica de una ontología que rechaza en el ser su desarrollo y dinamismo interno, constriñe luego al teólogo español a ampliar la

\footnotetext{
10 "Auctoris definitio. Tandem videtur obstare illi definitioni, quia potest Praelatus ordinare subditos secundum rectam rationem ad aliquid agendum, sufficienter proponendo communitati voluntatem suam, et nihilominus non ferre legem, quia non includit praeceptum perpetuum et stabile, quod diximus requiri ad rationem legis: unde tota illa definitio convenit praecepto communitati promulgato, etiamsi ad diem tantum propositum sit. Ad quod dico breviter, vel D. Thomas latius sumpsisse legem, et sub illa comprehendisse omne hujusmodi praeceptum, vel certe particulam primam ita intelligendam esse, ut ordinatio rationis pro illa tantum quae stabilis et duratura est, sumatur: unde posset fortasse brevius ita definiri: lex est commune praeceptum, justum ac stabile, sufficienter promulgatum. Illude nim genus posuit etiam D. Thomas, q. 96, art.

1 ad 2, et Jureconsultus, I. 1, de Legib., et per illud excluduntur praecepta particularia: per alias vero particulas indicantur omnia quae in lege desiderari possunt, ut facile patet consideranti ex his quae diximus" (5, 5, pp. 53-54).
} 
noción de la ley y a resaltar una paradoja: puesto que el acto debe ser libre, la ley debe ser obligatoria, y por tanto no inmanente, sino impuesta desde el exterior por una fuerza coercitiva ${ }^{11}$.

La postura de Suárez es en este sentido muy lógica: el carácter obligatorio de la ley no se manifiesta fuera de lo que es impuesto, y no puede ponerse en marcha por la sola consideración de un bien que hacer; se manifiesta exclusivamente en el poder de obligar a hacer ese bien. La ley es lo que conduce al acto por obligación. Puesto que la ley tiene como característica el ser obligatoria y obligar realmente, la noción de medida y de regla, característica de la reflexión del Aquinate, recibe en Suárez otro contenido: el acto está medido por la ley, no por la bondad objetiva que se expresa en ella, sino porque la prescripción crea la bondad del acto. Así, el acto resulta bueno porque es mandado.

La ley, por esto, como se deduce desde el principio del tratamiento del De legibus suareciano, en particular en los puntos 6 (Quae sit propria et vera lex) y 8 (Differentia inter legem, et consilium del capítulo I (Quid nomine legis significetur) del libro I, regula por qué impone y no por qué comprende y expresa (5, pp. 5-6). La regla (mensura) resulta, en efecto, praeceptum:

lex [...] debet esse talis ordinatio rationis, quae hoc modo procedat ab habente curam communitatis, ut in ipsa definitione declaratur; per se enim ac formaliter intelligenda est; [...] lex [...] per se est a superiore circa inferiorem, quod in definitione significatur: ita ergo sufficienter excluditur consilium a ratione legis. Et praeterea genus ordinationis intelligi debet de efficaci ordinatione, quae vim habeat cogentem, ut Aristoteles dixit; et hoc videtur etiam determinari per particulam promulgata, quia consilio non convenit proprie promulgari: nam haec vox indicat ordinem ad obligationem inducendam, in quo maxime differt consilium a lege (Suárez, Lib. I, cap. XII, 4, 5, p. 53).

Si vemos la aplicación de esto en las varias tipologías de leyes, en el cap. III (An lex aeterna sit actus divinae mentis, ratione ab aliis differens, et an una sit vel plures) del libro II (De lege aeterna et naturali, ac jure gentium) Suárez afirmará en seguida que la ley eterna en sentido propio se dirige a otras libres voluntades, a criaturas que pueden ordenar libres acciones (Suárez, De legibus, 7 y $8,5$, p. 94$)^{12}$.

Este modo de afrontar las cosas muestra así una orientación dispuesta a separar la ética, y por tanto, la libertad del sujeto, del orden ontológico. Suárez, criticando justamente el pensamiento de Vázquez, distingue el fin de la propia ley y mantiene así la relatividad de la ley en relación con un objeto, pero no llega a esta solución sino a través de la mediación del carácter obligatorio de la ley, es decir, separando la voluntad de un bien visto por el intelecto, hacia el cual la voluntad se lleva.

Se puede considerar la ley natural como el ser de la ontología suareciana, o sea, un bloque en el que la univocidad se expresa a través del proceso rigurosamente deductivo que saca las conclusiones de los principios. El sistema no puede soportar ningún cambio ni ninguna alteración, y por esto es inmutable y universal.

La ley natural, escribe Suárez en el cap VII ("In qua materia versetur lex naturalis, seu quae sint ejus praecepta") es una porque el hombre es un ser "uno" (Lib. II, cap. VII, 4) ${ }^{13}$, es una en cada hombre ${ }^{14}$, aunque no sea completamente conocida (Lib. II, cap. VII, 6) ${ }^{15}$,

\footnotetext{
${ }^{11}$ Se manifiesta ciertamente un retorno a la ética; mientras que en la perspectiva aristotélica la ética tenía un carácter autónomo, aquí comienza en cambio una concepción que reclama cada vez más la presencia de mandatos. En el primer caso, la ética terminaba en la inmanencia, en el segundo, termina, si es que termina, en la obediencia a la trascendencia, pero en sentido no filial sino servil.

12 "Lex aeterna formaliter consistit in decreto libero Dei statuentis ordinem servandum in partibus universi in ordine ad bonum commune" (Suárez, 1856, De legibus, 7 y 8, 5, p. 94).

13 "Resolvitur quaestio, et ostenditur jus naturale complecti omnia praecepta moralia, quae habent evidentem honestatem necessariam ad morum rectitudinem" (Suárez, De legibus, 5, p. 113).

14 "De his ergo omnibus intelligitur assertio posita: nam omnia haec ad legem naturalem pertinent; quod si id probatum fuerit, etiam de conclusionibus, cujuscumque gradus, dummodo evidentiae gradum certum attingant, a fortiori erit probatum de reliquis" (lib. II, cap. VII, 5) (Confirmatur assertio ratione) (Suárez, 1856, De legibus, 5, p. 113).

${ }^{15}$ Suárez F. (1856), De legibus, 5, pp. 113-114.
} 
es idéntica en todo tiempo y en todo lugar porque es expresión de la naturaleza misma, asimilada por Suárez a la quididad (quidditas).

Suárez desarrolla su doctrina de la participación de las leyes en una ratio idéntica. Piensa cada ley inferior según el modelo de la ley superior y, en efecto, llega incluso a confundirlas. Esto le lleva a considerar la ley natural como una realidad en sí que comprende el conjunto de la realidad, es decir, la ley eterna que deja lugar en ella misma a los decretos particulares, ni siquiera ordenados y no ya como una participación limitada del conocimiento humano en este orden ${ }^{16}$.

La unicidad de la ratio produce todos sus frutos: para el conocimiento de la ley natural captamos a costa de alguna deducción el orden universal. La participación humana, limitada, imperfecta, se sustituye por su modelo, que alcanza de manera adecuada. No hay ya distancia entre lo que está dentro de la realidad y lo que está dentro del espíritu; el misterio de la ley eterna es reemplazado por el sistema conceptual de la ley natural.

Suárez es fundamentalmente fiel a sus principios hasta las últimas consecuencias. La ley natural expresa la esencia de las cosas, que se desarrollan según esta quididad, y queda siempre adecuada a la totalidad de las realidades. A partir de los principios es posible alcanzar la totalidad de la realidad. La ley contiene una ratio que debe ser aplicada a todos los casos. Todos los casos en los que la ley se aplica son, por tanto, para Suárez, conocidos como continentes, a pesar de una diversidad aparente, de una ratio idéntica.

Esta posición marcará, en términos de filosofía del derecho, el abandono de una ley flexible, preparada para responder a la realidad en modos diversos y cuya aplicación sobrepasa la voluntad del legislador, condicionándolo parcialmente frente a la realidad. Suárez sustituye una noción de ley conforme a su metafísica. Puesto que la unidad de la ratio le permite considerar "a golpe de vista" la realidad, prevé así la posibilidad para el legislador de atender, en una única emisión de voluntad, a toda una serie de hechos, reducidos a idénticos.

La ratio de Suárez no es entonces un orden inmanente comprendido por la razón, según la equivalencia entre el ordo rerum y el ordo rationis planteada claramente por Tomás, sino un orden a priori que será inmediatamente aplicado a la cosa ${ }^{17}$.

Se perfila así un profundo vínculo entre el racionalismo de Suárez y su voluntarismo: este vínculo aparece aún más evidente leyendo el capitulo $X$ (Utrum perpetuitas sit de ratione legis) del libro I del De legibus en el que Suárez muestra que la ley es perpetua (vol. 5, pp. 4449). En el caso de las leyes humanas, Suárez opta por la perpetuidad, afirmando que la ley humana está dotada de una triple estabilidad moral, por parte del legislador, del sujeto y en sí misma.

Suárez fundamenta la estabilidad de la ley en la estabilidad de la voluntad legisladora, reconoce que hay movimientos y variaciones de las comunidades, pero estas son inmediatamente atribuidas a la sola materia, donde la causalidad muestra que esta juega un papel accidental ${ }^{18}$. Esta separación es la reanudación, a nivel de ley, de una oposición entre el orden del ser esencialista donde se devana la metafísica suareciana y la diversidad existencial de los entes y también la reanudación de la oposición entre intelecto y voluntad.

\footnotetext{
${ }^{16}$ Esto determina la llegada de una univocidad racional que se opone necesariamente a todas las trascendencias; Suárez aporta ya aquí a Grocio los elementos necesarios para elaborar el "etiamsi daremus Deum non esse", expresión que recibe aquí su verdadero fundamento metafísico.

${ }^{17}$ Está aquí la aplicación normal de la equivalencia de la razón a la cosa, que está en el centro de la epistemología suareciana.

18 "Tertia perpetuitas quae ex natura legis oritur. Tertia perpetuitas, scilicet, ut lex duret quamdiu non revocatur, vel materia ejus mutatur, hbet idem fundamentum, quia ad rectam gubernationem reipublicae necessaria sunt praecepta hoc modo stabilia, quae sint certae et permanentes regulae, ac mensurae operationum: haec autem praecepta significantur nomine legum, juxta usum jurium et doctorum; ergo" (Lib. I, cap. X, 15 5, p. 48).
} 


\section{Mauro Mantovani}

Por lo que respecta específicamente al tema de la ley, la teología moral más atenta y más sensible a la acusación de heteronomía retoma de la filosofía neoescolástica la categoría del derecho natural como fundamento racional, autónomo, de la ley moral, a partir de la tesis del ius naturale de Grocio: este, afirma, aunque creado por Dios, podría existir también si Dios no existiese (Grocio, 1751, Proleg., n.11). La tesis, ciertamente, no es indiferente respecto a las posturas de Vázquez y de Suárez.

Según Suárez, el derecho natural debe configurarse sobre un modelo matemático, como una construcción puramente racional a partir de la cual la razón humana pueda deducir los principios y las normas de comportamiento. De este modo, el derecho, a causa de su formalidad metafísica, tiene la pretensión de determinar con absoluta verdad la "naturaleza de las cosas", es decir, la finalidad intrínseca de cada una de las facultades humanas, de donde deducir la obligación moral y la naturaleza de las ordenaciones sociales.

De estas sintéticas notas sobre el concepto de ley en Suárez, podemos argüir la verificación de una etapa importante en el advenimiento definitivo de la concepción moderna de la ley. Su concepto de ley nace ante todo de una metafísica del concepto de ser que reconcilia la univocidad escotista y su opuesto, la equivocidad occamiana, en el ámbito de una dialéctica. De esta manera se retoma también la aspiración profunda que imprime el escotismo, o sea, la imposibilidad de salir de la dialéctica y por tanto de llegar a un orden, a no ser que se sacrifique lo singular a lo unívoco o lo universal al individuo.
Suárez desarrolla una metafísica del concepto de ser que llega a la unidad por medio de la participación de la ratio entis. El hombre entonces se encuentra encerrado en un mundo que no cesa de ser una amenaza para su libertad. En el plano ético se evidencia una dialéctica incurable, asimilable a la que subsiste en el plano del ser. La estructura paralela entre la metafísica del concepto del ser y la jerarquía de las leyes según un orden de participación es una exigencia interna del pensamiento de Suárez.

Por una parte, la metafísica exige que el ser se reconduzca a una jerarquía de determinaciones a las cuales corresponde una completa transparencia de lo real. Ahora, no se puede dar lugar a la preservación de la libertad si no se opone la voluntad al conocimiento: incluso la voluntad de crear y de legislar se oponen a la autocomprensión divina. Por otra parte, como las formas cada vez más particularizadas agotan el ser y toda la realidad equivalente a su o a sus conceptos cada vez más determinados, así el conocimiento de la voluntad del legislador es idéntico a la realidad; metafísica y ética se confunden en el formalismo.

En el cuadro ofrecido por Suárez se puede desplegar una jerarquía de leyes que se repiten, desde la ley eterna hasta la ley humana, con las mismas relaciones que existen al nivel del concepto de ser: unidad de participación a una ratio común. 


\section{Metafísica teológica}

\subsection{Suárez sobre la existencia y la subsistencia divina}

Comenzamos nuestra reflexión en materia de "metafísica teológica" suareciana ${ }^{19}$, haciendo referencia, ante todo, a un texto de nuestro autor poco posterior, es más, grosso modo contemporáneo a las Disputationes Metaphysicae, la Disputatio XI in quinque sectiones distributa: De divina existentia et subsistentia ${ }^{20}$. En él, el teólogo jesuita comenta la III Pars de la Summa Theologiae alternando - como suele hacer - a las quaestiones y articuli del Doctor Angélico, las disputationes, en las que explica la littera del teólogo dominicano. Suárez pretende tratar aquí la subsistencia, o sea, la existencia divina, y es evidente la intencionada conexión entre el texto de su documento y las Disputationes metaphysicae mismas.

Escribe, en efecto, el teólogo español:

Supponimus imprimis, ex iis quae in disputationibus metaphysicis, de existentia et subsistentia creaturarum dicuntur, communem rationem, seu significationem horum nominum, quia licet analogice de Deo et creaturis dicantur, tamen ratio nominum eadem est. Itaque nomine existentiae intelligimus illud esse, quod res habet ut sit aliquid in actu, seu actualis entitas distincta ab ente, quod tantum est in potentia objectiva, actu vero non est, seu nihil est; nomine vero subsistentiae intelligimus modum per se existendi. Supponimus deinde id, quod nostrae fidei fundamentum est, in Deo quidem tres personas, unam vero naturam seu essentiam reperiri, unde in disputationem cadit, pertineatne existentia et subsistentia in Deo ad unionem essentiae, an contra ad Trinitatem personarum, vel demum ad utrumque. Quae disputatio quamvis revera materiae de Trinitate sit propria, quia tamen mysterium, de quo agimus, sine illa intelligi non potest, ab hoc loco aliena consenda non est, cum praesertim a Theologis magna ex parte hoc loco discutiatur (1866, pp. 430-431).

Nos encontramos pues ante temas fundamentales de la doctrina cristiana, justamente porque a la discusión

\footnotetext{
${ }^{19}$ A título de ejemplo: Mahieu, L. (1921). François Suarez, sa philosophie et les rapports qu'elle a avec sa théologie, Paris: Desclée-Picard; Zappino, G. (1962). L'“Ego sum qui sum” (Exod. III, 14) nella esegesi di Francisco Suárez, (pro manuscripto). Roma: Pontificio Ateneo Salesiano; Honnefelder, L. (1989). Scientia trascendens: die Formale Bestimmung der Seienheidt und Realitat in der Metaphysik des Mittelalters und Neuzeit (Duns Scotus, Suarez, Wolff, Kant, Pierce). Hamburg: F. Meiner; Ortiz Ibarz, J.M. (1991). La participación como razón constitutiva del mundo: el constitutivo formal del ente finito según Francisco Suárez. Barcelona: Promociones y Publicaciones Universitarias; Fernández Burillo, S. (1997). Las Disputaciones metafísicas de Francisco Suárez S.J., su inspiración y algunas de sus líneas maestras: En el IV centenario de la primera edición (1597-1997). Revista Española de Filosofía Medieval, 4, 65-86; Murillo Murillo, I. (2003). Hablar y callar sobre Dios en Báñez, Suárez y san Juan de la Cruz. Cuadernos Salmantinos de Filosofía, 30, 243-275; Agostini, I. (2008a). L'infinità di Dio: Il dibattito da Suárez a Caterus (1597-1641). Roma: Editori Riuniti University Press; Agostini, I. (2008b). Oltre la distinctio rationis. L'inclusione reciproca degli attributi divini nella Scolastica moderna. Divus Thomas, 191 (51), 67-102; Agostini, I. (2010). Suárez, Descartes e la dimostrazione dell'esistenza di Dio, en M. Sgarbi (Ed.). Francisco Suárez and His Legacy (169-204). Milano: Vita e Pensiero; Coujou, J.-P. (2009). Durée et existence chez Suárez. Revue Thomiste 109, 589-620; Hoeres, W. (2012). Gradatio entis: Sein als Teilhabe bei Duns Scotus und Franz Suárez, Heusenstamm: Editiones Scholasticae; Colacicco, G. (2014). "Omnis causa est principium": un breve confronto tra la dottrina delle cause e la dottrina dei principi nelle Disputationes Metaphysicae di Francisco Suárez. Revista Filosófica de Coimbra 46, 263-292; Fastiggi, R. (1999). The Proof for the Existence of God in Suárez, en A. Cardoso, A. Martins y L. Ribeiro dos Santos (eds.) Francisco Suárez (1548-1617). Tradição e Modernidade (pp. 81-92). Lisboa: Ediçoes Colibri; Fastiggi, R. (2014). Suárez in Relation to Anselm, Aquinas and Scotus on Proving God's Existence, en L. Novák (Ed.) Suárez's Metaphysics in Its Historical and Systematic Context (309-323), Berlin: De Gruyter; Salas, V. (2014). Francisco Suárez, the Analogy of Being, and its Tensions, en L. Novák (Ed.). Suárez's Metaphysics in Its Historical and Systematic Context (87-104). Berlin: De Gruyter; Salas, V. (2015). Between Thomism and Scotism: Francisco Suárez on the Analogy of Being, en V. Salas y R. Fastiggi (Eds.). A Companion to Francisco Suárez (336-362). Leiden: Brill; Schmid, S. (2014). Suárez and the Problem of Final Causation, en L. Novák (Ed.), Suárez's Metaphysics in Its Historical and Systematic Context (293-308). Berlin: De Gruyter; Schmid, S. (2015). Finality without Final Causes? Suárez's account of Natural Teleology. Ergo 2 (16), 393-425; Darge, R. (2015). Suárez on the Subject of Metaphysics, en V. Salas y R. Fastiggi (Eds.). A Companion to Francisco Suárez (91-123), Leiden: Brill; Fink, J.L. (Ed.). (2015). Suárez on Aristotelian Causality. Leiden: Brill.

20 Suárez, F. (1866). Disputatio XI in quinque sectiones distributa de divina existentia et subsistentia. Opera Omnia, vol. 16 (pp. 430-457). En C. Berton (Ed.). (Editio nova). Paris: Vivès. El texto de este Comentario de la III Pars de la Summa Theologiae, facilitado por la edición Vivès, es la tercera edición - la definitiva, de 1595, publicada en Alcalá- edición que cita ya como textos paralelos las Disputationes Metaphysicae.
} 
de la existencia y subsistencia divinas se asocian aquí los dos misterios principales del cristianismo, o sea, los dogmas de la Trinidad y de la Encarnación.

$\mathrm{Si}$ consideramos las primeras tres secciones de la disputatio De divina existentia et subsistentia, deteniéndonos sobre todo en la primera (Utrum sit in Deo unum esse existentiae absolutum et essentiale), advertimos que resultan muy interesantes a nuestro objetivo, porque muestran de forma evidente la concepción o definición nominal que de Dios está proponiendo Suárez. Escribe el teólogo jesuita:

In Deo una existentia absoluta et essentialis. Dico igitur in Deo esse unum esse existentiae absolutum et essentiale commune tribus personis. Quae veritas tam certa mihi videtur, ut sine temeritate, et fortasse etiam sine errore negari non possit; nam primum in ea conveniunt omnes Theologi [...], et praesertim D. Thom. in ea est frequentissimus, nihil enim frequentius docet quam ipsum esse, seu existere, esse ipsam essentiam Dei, et loquitur non identice, sed formalissime, ut idem sit dicere esse essentiam, seu esse de essentia, seu esse praedicatum essentiale Dei, [...] hinc probat nomen, qui est, esse maxime proprium Dei, quia formaliter significat ipsum esse, quod est ipsa essentia Dei, et alia plura testimonia in sequentibus sectionibus citabo simul cum aliis Scholasticis. Nunc sufficienter probatur haec veritas ex hoc eodem nomine, qui est, seu, Ego sum qui sum, quod Deus sibi imposuit, Exod. 3 , adjunctis dictis et expositionibus Sanctorum, nam illud nomen, qui est, est nomen essentiale significans tres personas, ut sunt unus Deus (1866, s. I, n. 2, p. 431).

Al comentar el fragmento de la autopresentación de Dios a Moisés en Éxodo 3,14, Suárez cita, sí, a Santo Tomás, pero lo abandona bien pronto, para elegir en cambio a las auctoritates que puedan ofrecerle, mejor, una concepción de Dios en términos esencialísticos. De hecho, los Sancti por él citados son Dionisio, Agustín, Ruperto, Gregorio Magno, Bernardo, Ambrosio. Juan Crisóstomo, Basilio, Gregorio Nacianceno, Juan Damasceno, Atanasio, Gregorio de Nisa, Hilario,
Jerónimo: a todos estos Padres, el nombre de Dios Ego sum qui sum, induce a pensar en ciertas propiedades esenciales de Dios, en algo conceptualizable, como la aeternitas, la incommunicabilitas, el esse semper, la essentia, la natura existens. Esta elección fundamental, de tipo eminentemente metafísico, revela aquí la matriz más o menos secreta de la especulación suareciana en materias de grandísima importancia, como son la Santísima Trinidad y el Verbo Encarnado: esta, sin duda, determina e influye en los posteriores desarrollos especulativos del teólogo jesuita. La sententia de nuestro autor, que llega casi al final de la prima sectio, y que es probata etiam ratione, es particularmente indicativa:

Reliquum vero est ut etiam ratione sententiam positam demonstremus. Prima sumi potest ex omnibus allegatis testimoniis, quia in Deo una est aeternitas absoluta et essentialis [...]; ergo similiter est una existentia absoluta et essentialis [...]. Secunda ratio huic similis sumitur ex attributo immutabilitatis; est enim hoc attributum essentiale conveniens Deo ratione suae naturae infinitae; sed esse immutabilem includit essentialiter esse, seu existere, nam secundum rationem, necessario existere, supponit existere; immutabilitas autem inter alia dicit necessitatem existendi, quia necessaria permanentia in esse est primum ac praecipuum in immutabilitate; si ergo haec necessitas existendi formaliter est ex absoluta et essentiali perfectione Dei, multo magis ipsum existere. Tertio, quia esse seu existere, est perfectio simpliciter, ut videtur per se notum, quia sine dubio in qualibet re est melius ipsum quam non ipsum; sed omnis perfectio simpliciter in Deo est absoluta et essentialis [...], tum quia necessario esse debet communis omnibus personis; tum etiam quia de ratione entis summe perfecti est, ut includat formaliter omnem hujusmodi perfectionem; Deus autem essentialiter est ens summe perfectum; ergo esse seu existere est absoluta et essentialis perfectio Dei. [...] Quarto, potest hoc ita explicari, quia impossibile est, etiam per intellectum nostrum, praescindere essentiam Dei ab existentia actuali; ergo talis existentia est de essentia ipsius Dei (4, pp. 432-433). 
A la luz de estas reflexiones, las sectiones II y III de la Disputatio XI, respectivamente Utrum in Deo sit triplex esse existentiae relativum, seu an sint tre existentiae relativae (pp. 434-440), y Utrum in Deo sit aliqua subsistentia absoluta et essentialis (pp. 440-447) mostrarán las consecuencias de la definición esencialista de Dios en cuanto se refiere a la concepción de la Trinidad y de la Encarnación del Verbo, donde la disensión de Suárez con las posturas tomistas en cuestiones tan decisivas y cruciales resulta manifiesta.

La opción de Suárez sobre el modo de concebir a Dios o, en otros términos, la interpretación que del nombre Qui est acuña, a diferencia de Tomás de Aquino, lo coloca en una encrucijada en la cual se encuentran los máximos problemas de la sacra doctrina, y su decisión de proceder de un modo preferente a otro es la raíz de las sucesivas divergencias y alejamientos del sistema suareciano respecto a otros sistemas de pensamiento, partiendo del tomista.

\subsection{La demostrabilidad de la existencia de Dios}

Como ha escrito I. Murillo Murillo, "la posición de Suárez respecto al lenguaje sobre Dios aparece desarrollada en la sección tercera de la disputación XXVIII y en la sección decimotercera de la disputación XXX" (Murillo, 2003, pp. 257-258 ${ }^{21}$. Con la disp. XXVIII, dedicada a la primera división del ente en absolutamente infinito y finito, y otras divisiones equivalentes, Suárez empieza la segunda parte principal de las Disputationes Metaphisicae.

Es central, para el tema que estamos tratando, la consideración suareciana de la analogía.

De forma directa y sistemática la trata en dos secciones [...]: en la tercera sección de la disputación XXVIII, donde afronta la cuestión de la analogía del ser en general y la de la analogía entre Dios y la criatura en particular, y la sección segunda de la disputación XXXII, en que analiza la analogía de sustancia y accidente respecto al ente. No hay duda sobre la importancia que le da y la firmeza con que la defiende. Se la aplica a las cosas, a los conceptos y a los nombres. Alude a varios tipos de analogía y a sus partidarios. Piensa que no hay más que un sólo tipo de analogía que pueda aplicarse con verdad a Dios y a la criatura: la analogía de atribución intrínseca (Murillo, 2003, pp. 257-258).

El tema específico de la demostración de la existencia de Dios es afrontado por Suárez sobre todo en la disp. XXIX (De Deo primo ente et substantia increata, quatenus ipsum esse ratione naturali cognosci potest) $)^{22}$. En las disputationes inmediatamente sucesivas, la XXX (De primo ente, quatenus ratione naturali cognosci potest quid et quale sit) y la XXXI (De essentia entis finiti ut tale est et de illius esse eorumque distinctione) el teólogo jesuita pasa de la existencia divina a la relativa a la esencia, aun corroborando que "estas dos cosas no pueden separarse del todo en el conocimiento de Dios" (haec duo in cognitione Dei non possunt omnino seiungi) (DM, disp. XXX s. I, 1, vol. IV, p. 345).

Sin duda, la disp. XXXI es una de las que en mayor medida emerge la constante heterogeneidad, respecto del sistema tomista, de la especulación suareciana, pero no nos ocupamos de ello aquí, pensando que la heterogeneidad de las dos sistemaciones teológicas parte precisamente de la diferente definición de Dios.

Sintetizamos en cambio la disp. XXIX, que trata de Dios -el primer miembro de la división suarecianaafrontando la cuestión de su existencia, y se plantea ante todo el asunto de la posibilidad de demostrar la existencia de un ente increado por argumentos físicos o metafísicos para pasar después a examinar la pregunta de si se puede probar a posteriori la existencia de Dios demostrando que existe únicamente un solo ser creado, y concluirse discutiendo si se puede demostrar a priori de algún modo la existencia de Dios. Suárez aporta aquí una prueba racional de la existencia de Dios, diferente del argumento ontológico de San Anselmo, de las cinco vías de Santo Tomás y de las consideraciones de Juan

${ }^{21}$ El análisis de la postura de Suárez está presente en las pp. 256-264.

22 Para un comentario y presentación, ver al ya citado Mahieu (1921), pp. 189-201, y sobre todo Fastiggi (2014), pp. 316-323 (nota 19). 
Duns Escoto, aunque en relación con cada uno de ellos, R. Fastiggi escribe que "Suárez es un metafísico creativo e independiente. Aprecia las contribuciones de sus predecesores, pero con el ánimo de criticar, desarrollar y reforzar sus argumentos cuando es necesario" (2014, pp. 314-315).

La primera sección de la disp. XXIX está en relación, como afirma el propio Suárez, con dos temas: la posibilidad de la demostración, y con qué medio - físico o metafísico - demostrar, teniendo en cuenta que ambas cosas se pueden plantear respecto del ente increado y respecto de Dios, siendo en realidad lo mismo preguntarse por el ente increado que por Dios (quae duo de Deo etiam inquiri possunt, et in re idem est quaerere ens increatum et Deum). Para Suárez, la segunda es la opinión absolutamente verdadera, es decir, que la demostración pertenece solo a lo metafísico y no a lo filósofo natural, aunque también la cuarta opinión pueda reducirse a un sentido admisible (ad sanum sensum revocari).

Nuestro teólogo afronta primero directamente los argumentos físicos y luego los metafísicos, con los cuales se pretende probar la existencia de Dios. Suárez no acepta la primera vía de Santo Tomas, porque en su opinión, la premisa según la cual omne quid movetur ab alio movetur no tiene un valor universal2 ${ }^{23}$. El mismo tipo de respuesta es aportada por Suárez a propósito de la argumentación física relativa a las operaciones del alma racional y de la esencia de la misma (cf. nn. 18-19).

Pasando después al examen de los argumentos y de los medios metafísicos, Suárez afirma que se debe adoptar, en lugar del principio físico omne quod movetur ab alio movetur, el otro principio metafísico, mucho más evidente, omne quod fit, ab alio fit (todo lo que es hecho, es hecho por otro), principio demostrado por el hecho de que nada puede producirse a sí mismo: una vez que esté admitido este principio, afirma nuestro autor, la demostración llega a esta conclusión: todo ente o es hecho, o es no hecho o increado; mas no pueden ser hechos todos los entes que hay en el universo; luego es necesario que exista un ente no hecho o increado (DM, disp. XXIX, s. I, 21, vol. IV, p. 258).

Se trata, como bien advierte R. Fastiggi, de un argumento singular que une la segunda y la tercera vía de Santo Tomás, obrando de manera que la segunda vía incluya a la tercera (2014, p. 312).

La primera sección se cierra finalmente con la conclusión de que este ente increado debe ser por necesidad una sustancia (ens increatum necessario esse debere substantiam aliquam) y que por tanto existe alguna sustancia increada e inmaterial, pero -advierte el teólogo-,

si esa sustancia increada puede ser material por constar de otra materia, o si puede también ser corpórea como sustancia simple sujeta a la cantidad [...] creo que no puede determinarse solamente con el raciocinio que acabamos de exponer, sino que hay que avanzar echando mano de otros principios, como luego veremos; hasta ahora, pues, sólo hemos demostrado que existe alguna sustancia increada e inmaterial en el sentido explicado (s. I, 40, vol. IV, p. 273).

Para Suárez, entonces, es imposible demostrar con una argumentación estrictamente física la existencia de una sustancia increada o separada de todas las realidades materiales, mientras que ello es posible con una demostración metafísica. Nuestro autor llega así a la demostración de un ente increado, pero con ello no cree haber demostrado todavía la existencia de Dios, hasta el punto de que ahora es necesaria la segunda sección en la que se discute si se puede probar a posteriori que Dios existe demostrando que existe únicamente un solo ser increado.

${ }^{23}$ Ver también Fastiggi (2014), p. 311. 
El teólogo español observa, en efecto, al principio de la segunda sección, que las pruebas a posteriori de la existencia de Dios aportadas en la sección precedente no excluyen la posibilidad de que existan muchos entes causados, y por tanto no son suficientes para demostrar la existencia de un único ente incausado ${ }^{24}$. De alguna manera, la validez de la argumentación de la existencia de Dios debe ser valorada a la luz de la posibilidad de demostrar que el ser increado es único:

si llegamos a demostrar que este ente increado y esencialmente necesario sólo puede ser numerícamente uno según su naturaleza y esencia, brotará con claridad la consecuencia de que él es la primera causa de todos los demás que existen o pueden existir y que, por tanto, es Dios, y, en consecuencia, es el Dios verdadero (DM, disp. XXIX, s. II, 1, vol. IV, p. 275).

El maestro jesuita pasa ahora a su respuesta:

es posible demostrar con evidencia que el ente que es esencialmente necesario es la fuente o causa eficiente de las demás realidades y, que, por tanto, es uno solamente; y de esta suerte se demuestra con evidencia la existencia de Dios (DM, disp. XXIX, s. II, 4, vol. IV, p. 277).

En consecuencia, continúa el teólogo español en una de las afirmaciones más importantes de toda la sectio,

para demostrar la existencia de Dios no basta con probar la existencia en la realidad de un ente necesario y a se si no se prueba también que es único y con tales características que sea la fuente de todo ser, del cual depende y del cual lo reciben todos los demás que participan de algún modo del mismo ser. Una vez demostrado esto, queda suficientemente probada la existencia de Dios, puesto que los atributos restantes que se hallan en necesaria conexión con tal ente han de ser demostrados después (DM, disp. XXIX, s. II, 5, vol. IV, p. 278).
Por tanto, las cinco vías de Tomás por sí solas no habrían podido nunca demostrar la existencia de Dios.

Cuando el teólogo español llega a la conclusión de la segunda sección, enteramente dedicada a la valoración de una demostración a posteriori de la unicidad de Dios, afirma:

Confieso, sin embargo, que con esta objeción y con la precedente se llega a la convicción de que el raciocinio propuesto para demostrar que sólo existe un ente no producido y que todos los demás entes han sido producidos, no llega a una conclusión absoluta respecto de todos los entes, sino únicamente de aquellos que pueden ser objeto del conocimiento natural; por tanto, para que el argumento tenga valor de conclusión universal, hay que emplear necesariamente la demostración a priori (DM, disp. XXIX, s. II, 34, vol. IV, pp. 306-307).

Suárez no excluye pues radicalmente la posibilidad de la demostración de la unicidad de Dios, necesaria - recordémoslo- para completar la prueba de su existencia, pero excluye, como afirma I. Agostini:

que un intento de este tipo pueda ser realizado por medio de una prueba a posteriori. Está convencido de que se precisa una demostración a priori. Sólo con este auxilio las demostraciones a posteriori pueden concluir, universalmente, que sólo un ente puede ser la primera causa del universo (Agostini, 2010, p. 183).

Y es este el objeto de la tercera y última sección, en la que Suárez presenta el segundo camino para demostrar que existe Dios, que es inmediatamente a priori aunque remotamente sea también a posteriori (proxime a priori, quamvis remote sit etiam a posteriori). Ello pasa necesariamente a partir de la demostración a priori de la unicidad de Dios.

24 "Quamquam discursu facto praecedenti sectione evidenter probatum sit non posse omnia entia esse facta, sed aliquod esse non factum, quod vero hoc sit unum et non plura nondum est illa ratiocinatione conclusum”. DM, disp. XXIX, s. II, 1, vol. IV, p. 275. 


\section{Mauro Mantovani}

Hablando del valor de esta prueba a priori de la existencia de Dios, Suárez sostiene que una vez demostrado a posteriori que Dios es ente necesario y a se, se puede demostrar a priori desde aquel atributo que fuera de Dios no existe otro ente necesario y a se, y consecuentemente, demostrar la existencia de Dios. Suárez defiende su postura de la objeción de que se demostraría - de manera contradictoria - la existencia de Dios a partir de su quididad en cuanto tal, sino que

de un atributo que es en realidad la esencia de Dios, pero al que nosotros concebimos más abstractamente como un modo del ente no causado, se deduce otro atributo, y de esta suerte llegamos a la conclusión de que ese ente es Dios. Por eso, para llegar a concebir de este modo la existencia de Dios en cuanto Dios, se da por supuesto que ya está probada la existencia de un ente necesario por sí mismo, probada concretamente por sus efectos y por la negación del proceso al infinito. $Y$ de esta suerte, lo que primero se prueba respecto de este ente es su existencia, y después que es intrínsecamente necesario; desde aquí que es el único en tal razón y modo de existir y, por tanto, que es Dios (DM, disp. XXIX, s. III, 2, vol. IV, pp. 307-308).

Suárez es consciente de que esto implica la relación fundamental entre la cuestión an sit y la de quid sit, pero precisamente con tal fin ratifica que en Dios no pueden separarse totalmente las dos cuestiones, puesto que la existencia divina se identifica con la quididad divina, y las propiedades de la existencia de Dios, por medio de las cuales puede demostrarse que se trata del ser propio de Dios, constituyen la misma esencia y quididad divina.

La sectio tertia prosigue con la argumentación - esta vez a priori- y desarrollada con cinco demostraciones (cf. nn. 3-31), de que el ente de por sí necesario, no puede ser más que uno. Encontramos en el texto varias referencias a las vías de Tomás de Aquino y a los elementos en los que estas se apoyan, pero asumidos desde una perspectiva decididamente distinta.

En los últimos números de la sectio, Suárez saca los hilos del recorrido efectuado ex dictis omnibus conclusio, afirmando que las razones propuestas, consideradas conjuntamente, demuestran con absoluta suficiencia la verdad propuesta (simul sumptae sufficientissime praedictam veritatem demostrant), y son eficacísimas (efficacissimae), pero dispuestas en un modo bastante diferente respecto a los recorridos argumentativos que habían caracterizado los tres artículos, y sobre todo el tercero (An Deus sit) de la q.Il de la I Pars de la Summa del Aquinate a la cual también la disputatio XXIX, al menos implícitamente, pretendía referirse. 


\section{Conclusiones}

Hemos partido del concepto de ley y de sus referencias metafísicas en la lectura suareciana de Tomás de Aquino, advirtiendo un distanciamiento cada vez mayor de un concepto analógico de ley para llegar a una concepción de tipo dialéctico, aunque paradójicamente quería remitirse justamente a Tomás. Se puede identificar, en este sentido, un nexo importante entre Suárez y la modernidad en la consigna a Hobbes, a los filósofos de la edad moderna clásica, y al idealismo, de una noción de ley entendida sobre todo como orden de una autoridad, habiendo aportado, en cierto modo, las premisas nominalistas del pensamiento de estos.

Descartada pues, metafísicamente, la posibilidad de "aprehensión en el origen", la ley no puede más que resurgir dialécticamente bajo la forma de la intuición y de la voluntad arbitraria; la generalidad de la ley es suficiente para alcanzar, gracias a las restricciones o de la modalidad, el conjunto de las realidades reducidas a su aspecto formal, y por tanto reducidas a lo que representan para nosotros. Ello resulta, como se evidencia en un modo muy claro en las Disputationes metaphysicae, de una concepción ontológica según la cual en diversas ocasiones se excluye un "orden hacia un primero", para mantener solo un orden de participación en una noción común: todo ello, como hemos visto, no deja de incidir también en el tratamiento de la ley por parte de nuestro autor, que, en efecto - tras haber aportado su definición de ley-, examina en ella las realizaciones cada vez más degradadas, y a este examen se limita.

La cuestión fundamental, a partir de la ley, asciende no obstante el punto de vista metafísico, al hecho de que la analogía de la proporcionalidad haya sido reducida a una simple metáfora. Suárez propone un sistema que en pos del rechazo de la finalidad real, no puede ya comprender la unidad ordenada del mundo en su diversidad. Consecuencia es la necesaria división del mundo en dos dominios, el de las cosas naturales, o reino de la necesidad, aún más, de la fatalidad, y el de los seres racionales, sometidos por obediencia a otra voluntad. La noción tomista de una ley eterna que implica una direccionalidad de todo el universo desde su origen y hasta su final, parece ya caída en el olvido: ruptura y disociación resultan de la aplicación consciente de una ontología donde la causa final no encuentra ya suficiente espacio.

Mirando la vertiente de las nociones metafísicas de subsistencia y de existencia divinas, y de la demostrabilidad filosófica de la existencia de Dios, hemos advertido rápidamente cómo Suárez ha pedido prestadas las cinco vías de Tomás de Aquino. Según Fastiggi, que presenta en su estudio una esquematización en tres fases de la relación de Suárez con sus predecesores, las Disputationes Metaphysicae manifiestan una fase madura de la filosofía escolástica. Al probar la existencia de Dios, Suárez considera las perspectivas de sus predecesores medievales, pero su análisis de los temas es mucho más sutil y sofisticado. Motivo parcial de ello es su atención a las objeciones de pensadores como Occam y Pietro d'Ailly, que habían llegado después de Anselmo, Tomás de Aquino y Escoto (Fastiggi, 2014, pp. 315-316).

Advierte justamente Agostini:

Es dentro de un contexto global del cual forme parte integrante esta crisis del paradigma tomista de las cinco vías donde debe ser situada, históricamente, la postura suareciana; y en este sentido la intervención de Suárez sobre la cuestión, consignada en la XXIX de sus Metaphysicae disputationes, debería ser leída menos en términos de una ruptura radical introducida respecto a Tomás de Aquino, que en la radicalización de la inestabilidad del modelo de las cinco vías ya surgida en el seno de las discusiones teológicas contemporánea e, incluso, con Cayetano, dentro del mismo orden dominicano (Agostini, 2010, p. 197). 
Como hemos visto, para Suárez, la existencia y la unicidad de un ente que es la causa eficiente de todas las demás cosas puede ser demostrada con evidencia, y esta demostración equivale a probar que Dios existe. Pero como etapa preliminar requerida a la demostración, es necesario establecer el significado de la palabra "Dios", y esto hace que entre en juego necesariamente, si no el argumento ontológico, al menos una prueba a priori. Suárez, además, como ha escrito I. Agostini:

ha anticipado de alguna manera la posición de Descartes (subversiva, según afirmación propia del filósofo francés respecto del paradigma impuesto por las cinco vías de Tomás) al reconocer la necesidad de un conocimiento del quid sit de Dios antes del an est (Agostini, 2010, p. 189).

Son estrechas, en efecto, las relaciones - también en el tema de la existencia de Dios y de las pruebas - entre la reflexión del más grande metafísico de la Escolástica de la edad moderna y la del que ha sido calificado como el padre de la filosofía de la edad moderna, o sea efectivamente- entre Suárez y Descartes ${ }^{25}$.

En la obra metafísica del teólogo jesuita español es adoptado directamente el orden de la teología hasta el punto de excluir la analogía de la proporcionalidad, y de establecer una especie de neta homogeneidad entre la teología y la filosofía. Si la filosofía no se abre más a otro orden respecto al de la participación, si se ve obligada, para construirse, a renegar de la proporcionalidad, la teología a fortiori no podrá ya admitir en ella este otro orden por el que ha sido fecundada y puede ser, en cierto sentido, ayudada. Es justamente lo que ha aflorado de nuestras referencias a cómo Suárez considera que es, tanto la ley, como las pruebas de la existencia divina. En el corazón de esta aporía, nos parece, está precisamente el abandono del sentido de la existencia de una realidad situada más allá del sujeto, en la que se descubre, unida por un orden de fines hacia el primero, una efectiva diversidad de dimensiones.
La dificultad de pensar las mismas facultades dentro de un orden recíproco, remite de esta manera, en primer lugar, al problema de la separación entre lo verdadero y el bien, y favorece una dinámica de conflicto permanente entre los seres mismos, resultado de una más profunda dialéctica del ser, que se revela incapaz de salir de la univocidad. Frente al necesitarismo y a la univocidad de los átomos o de las razones, no le queda, por tanto, al sujeto más que intentar "dar la vuelta a las cosas" en su propio favor. La introducción de la potencia pasiva en Dios, por parte de Suárez, constituye pues el precio que hay que pagar por haber alejado del mundo finito la imperfección, por haber, en cierto, modo rechazado el orden de la potencia al acto.

El haber puesto a la luz esta ruptura de unidad metafísica onto-teológica resultante, puede constituir un estímulo para afrontar las principales problemáticas concernientes al campo filosófico en sentido estricto, como las relaciones entre derecho y ley, libertad y ley, conciencia y libertad, persona y trascendencia, advirtiendo el estrecho vínculo presente entre el pensamiento de la tardo escolástica y el de la modernidad. Se trata por ello de buscar una profunda unidad de teología, ontología y moral, de "real y racional", que una metafísica de la participación del acto del ser y de la finalidad permite encontrar. Escribe A. Alessi:

Lo existente se da como realidad eminentemente dinámica, eficiente, activa. Ipsum agere est esse. El universo no se resuelve en la suma de las perfecciones actualmente poseídas, no se resuelve en lo puramente dado de hecho o en la pura dádiva, sino que engloba un mundo de potencialidades, latentes pero no por ello irreales, que deben ser actuadas sobre todo con el concurso activo del hombre. Por ello el universo resulta, a la luz de la doctrina del acto y de la potencia, no sólo un don a aceptar con gratitud, sino un deber a cumplir con inteligencia y amor. El conjunto de lo que existe no es un museo a contemplar sino una obra a construir (Alessi, 1992, p. 329).

\footnotetext{
${ }^{25}$ Cf. por ejemplo, a tal propósito, Scribano, E. (1994). L'esistenza di Dio, Storia della prova ontologica da Descartes a Kant. Roma-Bari:
} Laterza, sobre todo las pp. 99-111; Agostini (2010), pp. 169-204. 
En cualquier caso, necesitamos un pensamiento unitario y armónico, fuerte no por la capacidad coercitiva o por la consistencia externa del aparato que lo sostiene, sino porque está siempre mejor medido por las cosas y por su efectiva realidad.

\section{Referencias}

Abbà, G. (1983). Lex et virtus. Studi sull'evoluzione della dottrina morale di San Tommaso d'Aquino. Roma: Las.

Abbà, G. (1995). Figure di etica: la filosofia morale come ricerca delle regole per la collaborazione sociale. Salesianum, 57, pp. 251-281.

Agostini, I. (2008a). L'infinità di Dio: Il dibattito da Suárez a Caterus (1597-1641). Roma: Editori Riuniti University Press. Agostini, I. (2008b). Oltre la distinctio rationis. L'inclusione reciproca degli attributi divini nella Scolastica moderna.

Divus Thomas, 191 (51) pp. 67-102.

Agostini, I. (2010). Suárez, Descartes e la dimostrazione dell'esistenza di Dio, en M. Sgarbi (Ed.). Francisco Suárez and His Legacy (169-204). Milano: Vita e Pensiero.

Alessi, A. (1992). Metafisica. Roma: Las.

Ambrosetti, G. (1948). La filosofia della legge di Suarez. Roma: Studium.

Andereggen, l. (2011). El bien metafísico fundamento de la ley, según Francisco Suárez. Divinitas, 54 (3), pp. 257-274.

Arntz, J. (1970). Lo sviluppo del pensiero giusnaturalistico all'interno del tomismo, en F. Boeckle (Ed.). Dibattito sul diritto naturale (pp. 115-148). Brescia: Queriniana.

Bach, O., Brieskorn, N. y Stiening, G. (Eds.). (2013). “Auctoritas omnium legum”: Francisco Suárez’ De legibus zwischen Theologie, Philosophie und Jurisprudenz. Stuttgart, Bad Cannstatt: Frommann Holzboog.

Bastit, M. (1989). Interprétation analogique de la loi et analogie de l'être chez Suárez: de la similitude à l'identité. Les Etudes philosophiques, 44, pp. 429-443.

Bastit, M. (1990). Naissance de la loi moderne. La pensée de la loi de saint Thomas à Suárez. Paris: PUF.

Blázquez Fernández, N. (1989). Tratado de la ley antigua y nueva, en Tomás de Aquino, Suma Teológica, Madrid: BAC, II, pp. 761-776.

Carbonnier, J. (1979). L'inflation des lois: Essais sur les lois. Paris: Presses Universitaires de France.

Cardoso, A., Martins, A. M. y Ribeiro dos Santos, L. (Eds.). (1999). Francisco Suárez (1548-1617): Tradição e Modernidade. Lisboa: Ediçoes Colibri.

Castellote, S. (1980). Der Stand der heutigen Suárez-Forschung auf Grund der neu gefundenen Handschriften. Philosophisches Jahrbuch, 87, pp. 134-142.

Colacicco, G. (2014). "Omnis causa est principium”: un breve confronto tra la dottrina delle cause e la dottrina dei principi nelle Disputationes Metaphysicae di Francisco Suárez. Revista Filosófica de Coimbra 46, pp. 263-292.

Contreras, S. (2012). La ratio legis en la teología de Suárez y Santo Tomás. Teología y Vida, 53 (4), pp. 503-520.

Cotta, S. (1955). Il concetto di legge nella Summa Theologiae di San Tommaso d'Aquino. Torino: Giappichelli.

Coujou, J.-P. (2009). Durée et existence chez Suárez. Revue Thomiste 109, pp. 589-620.

Coujou, J.-P. (2010). Bibliografía suareciana. Pamplona: Universidad de Navarra.

Coujou, J.-P. (2012). Droit, anthropologie \& politique chez Suárez. Perpignan: Artège.

Coujou, J.-P. (2015). Political Thought and Legal Theory in Suárez, en V. Salas y R. Fastiggi, (Eds.). A Companion to Francisco Suárez. Leiden: Brill, pp. 29-71.

Courtine (1979). Le projet suarézien de la métaphysique. Archives de Philosophie 42, pp. 237-274.

Darge, R. (2015). Suárez on the Subject of Metaphysics, en V. Salas y R. Fastiggi (Eds.). A Companion to Francisco Suárez), Leiden: Brill, pp. 91-123. 
Fink, J.L. (Ed.). (2015). Suárez on Aristotelian Causality. Leiden: Brill.

Desjardins, C. (1963). Dieu et l'obligation morale: L'argument déontologique dans la scolastique récente. Paris: Descleé.

Editorial (1949). Suárez, modernité traditionelle de sa philosophie. Archives de Philosophie, 18, pp. 4-6.

Faraco, C. (2013). Breve excursus sul concetto di legge in Francisco Suárez. Colonne Ofitiche:Percorsi di ermeneutica simbolica, Napoli: Luciano, pp. 73-84.

Farrell, W. (1930). The natural moral law of S. Thomas and Suarez. Ditchling: St. Dominic's Press.

Fastiggi, R. (1999). The Proof for the Existence of God in Suárez, en A. Cardoso, a. m. Martins y L. Ribeiro dos Santos (Eds.). Francisco Suárez (1548-1617). Tradição e Modernidade. Lisboa: Ediçoes Colibri, pp. 81-92.

Fastiggi, R. (2014). Suárez in Relation to Anselm, Aquinas and Scotus on Proving God's Existence, en L. Novák (Ed.). Suárez's Metaphysics in Its Historical and Systematic Context Berlin: De Gruyter, pp. 309-323.

Fernández Burillo, S. (1997). Las Disputaciones metafísicas de Francisco Suárez S.J., su inspiración y algunas de sus líneas maestras: En el IV centenario de la primera edición (1597-1997). Revista Española de Filosofía Medieval, 4, pp. 65-86.

García Cuadrado, J. A. (Ed.). (2014). Los fundamentos antropológicos de la ley en Suárez. Pamplona: Eunsa.

Giacon, C. (1946). La Seconda scolastica. Milano: Fratelli Bocca.

Grabmann, M. (1926). Die Disputationes Metaphysicae des Franz Suarez in ihrer methodischen Eigenart und

Fortentwicklung, en M. Grabmann (Ed.). Mittelalterliches Geistesleben. Abhandlungen zur Geschichte der Scholastik und Mystik, München: Max Hueber, pp. 525-560.

Grocio, H. (1751), De iure belli ac pacis. Lausannae: Bosquet.

Hill, B. y Lagerlund, H. (Eds.). (2012). The Philosophy of Francisco Suárez. Oxford: Oxford University Press.

Hoeres, W. (2012). Gradatio entis: Sein als Teilhabe bei Duns Scotus und Franz Suárez. Heusenstamm: Editiones

Scholasticae.

Honnefelder, L. (1989). Scientia trascendens: die Formale Bestimmung der Seienheidt und Realitat in der Metaphysik des Mittelalters und Neuzeit (Duns Scotus, Suarez, Wolff, Kant, Pierce), Hamburg: F. Meiner.

Kirstin, B., Fuchs, M.J., Simmermacher, D. y Spindler A. A. (Eds.). (2016). The Concept of Law (lex) in the Moral and Political Thought of the 'School of Salamanca'. Leiden: Brill.

Larrainzar, C. (1976). Una introducción a Francisco Suárez. Pamplona: Eunsa.

Mahieu, L. (1921). François Suarez: Sa philosophie et les rapports qu'elle a avec sa théologie. Paris: Desclée-Picard. Mesnard, P. (1949). Comment Leibniz se trouve placé dans le sillage de Suárez. Archives de Philosophie, 18, pp. 7-32.

Moita, G.P. (2014). A Modernidade Filosófica de Francisco Suárez, Lisboa: Imprensa Nacional-Casa da Moeda; Novák, L. (Ed.). (2014). Suárez's Metaphysics in Its Historical and Systematic Context. Berlin: De Gruyter.

Murillo Murillo, I. (2003). Hablar y callar sobre Dios en Báñez, Suárez y san Juan de la Cruz. Cuadernos Salmantinos de Filosofía, 30, pp. 243-275.

Murphy, M.C. (2014). Suárez's ‘Best Argument’ and the Dependence of Morality on God. Quaestiones Disputatae, 5 (1), pp. 30-42.

Ortiz Ibarz, J.M. (1991). La participación como razón constitutiva del mundo: el constitutivo formal del ente finito según Francisco Suárez. Barcelona: Promociones y Publicaciones Universitarias.

Osuna Fernández-Largo, A. (1989). Tratado de la ley en general, en Tomás de Aquino, Suma Teológica, Madrid: BAC, II, pp. 693-702.

Owen, H.P. (1965). The moral argument for Christian Theism, London: Allen.

Owens, J. (1957). Common nature: a point of comparison between thomistic and scotist metaphysics. Medieval Studies, 19, pp. 1-14.

Pace, P. (2015). Suárez and the Natural Law, en V. Salas y R. Fastiggi R. (Eds.). A Companion to Francisco Suárez. Brill, Leide, pp. 274-296. 


\section{"Metafísica jurídica" y "metafísica teológica"}

Pereira, J. (2007). Suárez: Between Scholasticism and Modernity. Milwaukee: Marquette University.

Poncela, G.Á. (2012). Una aproximación bibliográfica a Francisco Suárez como comentador de la Suma Teológica.

Cauriensia, 7, pp. 165-173.

Roth, R. (1980). Moral obligation and God. The Newscolasticism 54, pp. 265278.

Roth, R. (1985). Moral obligation: With or without God. The Newscolasticism, 59, pp. 471-474.

Salas, V. (2014). Francisco Suárez, the Analogy of Being, and its Tensions, en L. Novák (Ed.). Suárez's Metaphysics in Its Historical and Systematic Context). Berlin: De Gruyter, pp. 87-104.

Salas, V. (2015). Between Thomism and Scotism: Francisco Suárez on the Analogy of Being, en V. Salas y R. Fastiggi (Eds.). A Companion to Francisco Suárez. Leiden: Brill, pp. 336-362.

Salas, V. y Fastiggi, R. (Eds.). (2015). A Companion to Francisco Suárez. Leiden: Brill.

Schmid, S. (2014). Suárez and the Problem of Final Causation, en L. Novák (Ed.), Suárez's Metaphysics in Its Historical and Systematic Context. Berlin: De Gruyter, pp. 293-308.

Schmid, S. (2015). Finality without Final Causes? Suárez's account of Natural Teleology. Ergo 2 (16), pp. 393-425.

Schwartz, D. (Ed.). (2012). Interpreting Suárez: Critical Essays. Cambridge: Cambridge University Press.

Scribano, E. (1994). L'esistenza di Dio, Storia della prova ontologica da Descartes a Kant. Roma-Bari: Laterza.

Sgarbi M., M. (Ed.). (2010). Francisco Suárez and His Legacy. Milano: Vita e Pensiero.

Suárez, F. (1856-1878). Opera Omnia (Editio nova), M. André y C. Berton (Ed.). Paris: Vivès.

Suárez, F. (1856). Tractatus de Legibus, Opera Omnia (Editio nova), C. Berton (Ed.). Parisiis Vivès, vol. 5-6.

Suárez, F. (1962). Disputaciones Metafísicas [DM], S. Rábade, S. Caballero Sánchez y A. Piugcerver Zanón (Eds.). Madrid: Biblioteca Hispánica de Filosofía-Gredos.

Suárez, F. (1866). Disputatio XI in quinque sectiones distributa de divina existentia et subsistentia, in Opera Omnia C. Berton (Ed.). (Editio nova). Paris: Vivès, vol. 16.

Tomás de Aquino (1989). Suma Teológica, Madrid: BAC, II.

Vázquez, G. (1600). Commentaria ac disputationes in Summa Theologiae Sancti Thomae Aquinatis. Venetiis: Baretium \& socios.

Velázquez, L. (2014). Presupuestos antropológicos de la concepción de la ley natural en Suárez (a propósito de Dios creador/legislador) en J.A. García Cuadrado (Ed.). Los fundamentos antropológicos de la ley en Suárez. Pamplona: Eunsa, pp. 75-88.

Zappino, G. (1962). L'“Ego sum qui sum” (Exod. III, 14) nella esegesi di Francisco Suárez, (pro manuscripto). Roma: Pontificio Ateneo Salesiano. 